\title{
Universal Design - A Solution for Ageing Workforce in Digitalized Workplaces?
}

\author{
Rudolph BRYNN \\ Universell Utforming AS
}

\begin{abstract}
This study reviews the extent to which Universal Design of digitalized work tools is not only a useful, but a necessary principle to support inclusion in an ageing workforce. But Universal Design must be understood and implemented in a broader sense than "classic" adaptation. It includes areas like services, digitalization training and user interface between mainstream and assistive technologies. It makes requirements to an enterprise's management system and training policy, besides mainstream human resources policies. The paper goes through these requirements and concludes with the need to improve our understanding of the principle of Universal Design for it to be an efficient tool for inclusive workplaces: not only the digital work tools have to be accessible, but it must be combined with management policy, training and support.
\end{abstract}

Keywords. Ageing workforce, universal design, accessibility, inclusiveness

\section{Introduction}

The demographic development in Europe, and indeed throughout the world, shows that an increasing part of the world's population is ageing, and this includes persons in the global labor market. At the same time, digitalization of work tasks and the use of ICT is to an increasing degree dominating many types of work. How will this affect elderly workers? Will new technology create new barriers, especially for workers with permanent or age-related disabilities? Or can accessibility and universal design of digital systems provide a tool strong enough to remove or reduce such barriers?

This paper will look into the principle of universal design of digitalized work tools and the different aspects of this, to ensure a successful integration of older workers into the labor market and to workplaces - that is, to keep the experience of existing workers and to benefit from hiring older workers.

Questions that will be asked are:

- What is universal design in the context of digitalization of workplaces?

- Is universal access - with an emphasis on digitalization - an efficient enough tool to ensure inclusion of older workers in an ageing workforce?

- If so, is accessible ICT sufficient or must it be seen in a broader context?

The background for this paper is ongoing work in Norway on developing national standards in the field of digitalization and elderly people in society, including inclusive labor market, Smart Cities and Internet of Things in which the author is working, as well as Nordic and European projects in which the author takes part. 


\section{Project background}

The ageing society is also affecting work life, with more workers continuing in their jobs for longer. Arguments regarding this development span from fear of older workers being more expensive and less productive than others, to older workers in a workplace yielding improvements in staff engagement and motivation, solving problems of lack of workers and enterprises benefiting from linking new and existing skills by raising productivity and innovation capacity.

However, an ageing workforce require several measures from the part of the enterprises and management to ensuring success and fulfil the potential of the workers. This includes several types of measures, from human resource management policy, integration mechanisms and success measuring, to adapting a workplace physically.

The inclusive workplace realizes a large societal benefit - not least because it contributes to more people entering the labor market, that more people can benefit from others' experiences and stay at work longer, a sustainable work life. It also provides enterprises with increased possibilities to reach their objectives and thereby increase their competitive abilities. For the individual it is a possibility for financial safety and selfrealization. An important part of achieving an inclusive work life is through accessibility and universal design.

\section{Method used}

The method that has been used in the project is qualitative methodology, first and foremost study of secondary sources and textual analysis, as well as web-based discussions with several experts during the various projects that make the basis for this paper. The sources studied includes Nordic and international documents and studies related to the topics discussed herein. The References list the primary sources both describing employment issues and accessibility, and technical solutions and their possibilities and possible limitations.

\section{Theoretical background: Definition of Universal Design}

Universal Design, or Design for All, is understood as a tool for creating a barrierfree society for all, and to combat discrimination in the shape of barriers against accessibility. Here, the recent European standard EN 17161 Design for All Accessibility following a Design for All approach in products, goods and services Extending the range of users is important to understand the methodology of universal design in general. [1]

The principle of universal design has been defined in a broader sense; including not only physical environments but also in areas like services, digitalization and others - to test out how useful it is in the field of older workforce.

Accessibility is one of the general principles of the UN Convention on the Rights of Persons with Disabilities (UN CRPD), a precondition of equal access to enjoy all the rights enshrined in the Convention. Moreover, universal design or design for all - is defined in the UN CRPD as "the design of products, environments, programs and services to be usable by all people, to the greatest extent possible, without the need for adaptation or specialized design. "Universal design" shall not exclude assistive devices 
for particular groups of persons with disabilities where this is needed" [2]. Thus, by applying a Universal Design or Design for All approach, organizations of all kind can achieve greater accessibility outcomes.

In the European Standard EN 17161 the same definition from the CRPD is used. "Accessibility" is defined as "extent to which products, systems, services, environments and facilities can be used by people from a population with the widest range of user needs, characteristics and capabilities to achieve identified goals in identified contexts of use". [3]

\section{What is universal design regarding digitalization in workplaces?}

First and foremost, it is important to remember that elderly workers are far from a homogenous group - like any group of workers. People face different challenges according to their personal background, education, and experiences - some will be experts in digital work tools, others not. The issue of universal design of digitalized work tools can seem to be mostly relevant for employees having disabilities, either age-related or permanent. However, every one of us will face challenges with higher age - and notwithstanding our personal competence, universal design will be helpful for many to be able to continue to work.

In workplaces where digitalization is used, there are several challenges for elderly employees. In larger enterprises there may be several different platforms, file structures, SharePoint and others, and these can be difficult for those not familiar with the systems. Accessible information is needed to find out where to find and use the necessary services. The following is a general overview of systems and working tools with a focus on which application strategy to have.

Universal design in workplaces includes multiple factors:

- the physical framework surrounding the workplace, like the built environment and adjacent outdoor areas, physical elements at the workplace itself (interior, access to a lift and handicap toilet, adaptable desk etc.);

- digital tools for use at work, like computers, laptops, mobile applications, speech synthesis and software like internet and intranet;

- $\quad$ accessibility to services connected to the workplace, including many factors from management policy to training and performance of services.

\section{Empirical evidence - digitalization as a challenge or tool for inclusion?}

As a point of departure, to ensure an inclusive workplace for older workers, the management of an enterprise or workplace should have an adopted age-inclusive policy to state the objectives of their human resources initiatives, training programs and likewise. This also includes performance reviews and informal meetings as well as flexible arrangements for older workers.

But regarding accessibility it is most relevant to focus on workplaces in the physical sense. This includes not only the work premises but also work tools like digitalized systems, software and hardware as well as automats. The management must in this regard develop a program for accessibility and adaptation of workplaces to ensure barrier free surroundings, for which there are plenty of regulations and guidelines. 
Physical adaptation of the workplace is not enough to ensure an inclusive working environment for an ageing workforce. In an age of digitalization, it is important to ensure that an enterprise has accessible digital technologies and systems through their procurement policy. But in addition, the training of staff in the use of digital systems

is vital to ensure digital literacy. This includes training in the use of remote systems, artificial intelligence, machine learning, real-time data, Internet of Things and robotics.

In addition, support and training for workers, including elderly workers, is necessary to ensure the full use on equal basis of the systems. Also, it must be ensured that there is a good interconnection between the systems and the individual assistive technology of workers, for instance in the case of Braille terminals (see below).

\section{What kind of technologies are available?}

There are plenty of digitalized technological innovations and solutions available.

However, the report Ageing workforce management in manufacturing systems: state of the art and future research agenda shows that there is limited research around seniors in the workplace. [4]

When it comes to requirements for workers, this applies to increased requirements for digital competence. But at the same time, the proper use of technology can help relieve workers. For example, competence building can take place through web-based events. In some cases, for example, visualization technology can be used to show how tasks can be worked out.

Thus, requirements for workers with disabilities will therefore include:

- Good access to technical aids (see separate sections on this).

- Good access to training in accessible formats.

- Flexibility in terms of tasks, time spent, etc. to keep employees in work.

- One must solve problems regarding that the digital systems used in the workplace can become dominant, and that there is consequently reduced influence on the work performance from the part of individual worker. This will lead to increased effort to adapt to the needs of elderly workers with disabilities.

- One aspect of the use of digital technology is that power relationships in businesses are transferred to technical experts regarding control over the work processes. This must be addressed by a focus on individual adaptation as far as possible.

- Robots can contribute to the relief of work requirements; this can benefit elderly workers with disabilities.

- Robots can be programmed to detect, recognize and react to unpredictable or too fast movements in humans, which can, for example, be caused by disabilities and thus help avoid mishappenings and accidents.

- Digital technology can be used to increase safety in work situations, such as alarms mounted in clothes or mobile devices that can provide workers with aid and assistance.

- E-learning in accessible format will strengthen the opportunities for competence building among employees with disabilities.

- Computer simulation can study various forms of physical load and ergonomic consequences. This can be used, among other things, in ergonomic design of the workplaces. 
- Algorithms can be used to develop decision systems that promote better ergonomic conditions in the workplace - you can allocate tasks according to the physical requirements and loads of different workers and contribute to optimal distribution of tasks, regardless of impairments.

- It is important to systematically ensure user participation when new technology is introduced, such as robots, so that those employees who are affected can be involved in the technological development, the implementation and use of the technology and its updating. If this is not done, staff may be excluded, for instance because consideration was not given that elderly workers with disabilities have the required ability to participate in the processes.

There is no space here to give an exhaustive list of technological systems, but we will mention some examples to illustrate the challenges connected to their use for persons with different types of impairments. Some of these examples also illustrate the particular issues connected to "smaller" language groups, when the system is based on the English language.

Table 1. Type of technologies and accessibility issues

Type of technology

Accessibility issues

Smart phones, iPhones

Mobile applications

Hearing aids
Screen views are empty for the screen reader because nothing is read aloud.

Focus changes make it difficult to use

synthetic speech.

Controls that cannot be assessed through switches control.

Contrasts are hard or impossible to read for persons with reduced contrast view.

Buttons and other controls lack textual description.

Inaccessibility for those using screen reader, switch controls and other assistive technologies. Developers are unfamiliar with the universal design methodology.

Lack of training possibilities for users of applications.

Inadequate descriptions of updates of applications.

Long time between updates that improve accessibility.

Many applications that are important in work life, like bank- or travel applications, do not function e.g. with VoiceOver.

It is necessary to have a good system for reactions from application users.

At meetings it is a challenge when multiple people speak simultaneously. At digital meetings this is easier as long as those who are not talking, are muted 
Hearing aid loop

Writing interpreter equipment

Tools for automatic speech to text function

Intranet

Data programs, for instance for data analysis, production of content and others

Speech synthesizers

Braille terminal, screen readers

Text-to-speech functions

Speech to text functions

Automatic translation from one language to another

Automatic simplification of content
Requires that one person at the time speaks into the microphone.

Inaccessibility

The equipment is often functioning bad, in particular for those using Nordic languages - the technology is adapted to English spoken language.

Intranet pages are often not universally designed, like extranet pages usually are.

Data programs and other equipment for, for instance, analysis are not accessible and exclude certain employees.

There has been a lack of Nordic speech synthesizers on existing technology, because the market is too small for the producers.

PDF format on electronic documents is a problem if they are not tagged correctly. Then a Braille terminal is not able to interpret the content of the document correctly and may for instance read across columns instead of downwards in every column.

Word documents that are saved as PDF documents cannot be read on Braille terminals. A Braille terminal only shows letters and signs, but not graphical elements. In text-based operative systems like for instance UNIX or DOS this is very simple, but in graphical operative systems like for instance Windows and Mac OS this is a greater challenge. Since the Braille terminal is limited to only represent one text line at the time, the Braille terminal has to find the focal point of the active window. The focal point is normally where the text marker is or the active dialogue box.

Producers often do not make systems in Nordic languages but are based on English Language.

Producers often do not make systems in Nordic languages but are based on English Language.

Often based on English language. The functions do not analyze the complexity level of the language.

Often based on English language. The functions do not analyze the complexity level of the language. 
Machine learning - machines learn automatically to recognize complex patterns and to make intelligent decisions based on data. A learning algorithm uses a set of training data to develop or improve a type of behavior. One problem is the fact that all kinds of behaviors, given the multitude of impressions, are too many to be covered by the mass of observed examples. The algorithm must, then, be able to generalize, and find solutions for problems that it has not observed examples of, previously.

Mobile applications, for instance Microsoft Seeing AI that describes the surroundings for the user, especially designed for visually impaired people. Describes people, texts and objects [5]

Real-time speech-to-text translation function for deaf and hard of hearing persons [6].

OrCam MyEye - this is a small camera with inbuilt text-to-speech function. It can be attached to your spectacles frame and it will read text, barcodes and recognize faces in front of you. With minor hand movements the OrCam will take a picture of that which the camera is pointing to, and then start and stop reading aloud according to the hand movement which is made. The OrCam is developed for blind and persons with severe visual impairment but can also be an assistive technology for children with great reading and writing difficulties.
Exactitude and width in recognizing patterns for various types of disabilities.

Exactitude and usefulness for blind and visually impaired people

Exactitude for deaf and hard of hearing persons.

Exactitude for blind and visually impaired persons, and usefulness for persons with multiple disabilities.

\section{What to require of digitalization technologies to ensure inclusive workplaces?}

There are several guidelines for ensuring universal design of ICT, for instance the European standard EN 301549 Accessibility requirements suitable for public procurement of ICT products and services in Europe [7]. But in addition to this it is necessary to focus on the seamless interface between such technology and work tools and assistive technology used by individual employees. Today there are many personal assistive devices like hearing aids and magnifying glasses, and adaptive personal assistive devices to make mainstream technology accessible for persons with disabilities, like screen readers for computers. On national level, a project is for instance going on in Norway on developing standards to ensure accessibility for elderly persons in society, including workplaces, Internet of Things and Smart Cities [8].

Besides following standards and guidelines, it is however necessary to have full understanding of who are responsible for ensuring an inclusive labor market. The overall responsibility lies with public authorities, through a good policy on public procurement 
to make guiding lines for producers and providers of goods, products, and services, regarding the accessibility of what they offer. Here, a systematic use of user participation should also be useful. In addition, the public authorities are in the Nordic countries often responsible for making available assistive technology, provide funding for adaptation and other public support systems [9].

At the next level, the management of the enterprises themselves are of course responsible for making possible an inclusive workplace for all employees. This requires a policy for making the enterprise inclusive, and planning and implementing measures to assure this, through procurement of work systems, training of staff and ensuring the individual needs for training, support, and others for the employees. This will yield several benefits:

- improved customer relations with elderly and persons with disabilities, their families and friends;

- $\quad$ improved market response and access to customers;

- improved access to more resources and talents in the shape of elderly persons, especially those with age-related disabilities;

- improved innovation and customer services;

- legal advantages;

- financial benefits both for the enterprise and on national level as elderly and disabled employees contribute to the economy in general and to ensure greater economic equality;

- professional benefits for employers, through the development of improved technical competence, job design, accessibility and other elements [10].

The policy of the management of enterprises should include recruitment, for instance Case Management, Motivating Interviews (MI) [11] or Job Carving, providing support, mentors and coaches, adaptors etc. at employment, as well as individual adaptation of work tasks, the availability of assistive technology, AI equipment, robots etc. There is, however, limited research on this [12].

The challenges to managers with a policy for inclusive workplace can be summed up as:

- $\quad$ good access to training, in accessible formats;

- flexibility regarding tasks, use of time to perform tasks etc., to keep employees with impairments;

- solve problems with digital systems at the workplace, when these are controlling the work processes, there is a risk for employees who are not able to use them, to be excluded from the performance of work tasks;

- focus on individual adaptation as far as possible;

- use robots for relief of work demands that are physically challenging;

- robots can be programmed to recognize too quick or unexpected movements with humans, that may be caused by disabilities and thus help to avoid accidents;

- digital technology can be used to improve security in work situations, like alarms installed in clothing or mobile units that can provide employees with help and assistance;

- e-learning in accessible formats will strengthen the possibilities for competence development with employees; 
- data simulations can study different forms of physical stress and ergonomic consequences, this can be used for instance for ergonomic adaptation of workplaces;

- algorithms can be used to develop decision making systems that yield improved ergonomic conditions at the workplace - it is possible to distribute work tasks according to the physical demands and burdens and may contribute to an optimal distribution of tasks, disabilities notwithstanding;

- ensure systematic user participation when new technology is introduced.

In addition, there are challenges regarding the interface between mainstream technology and assistive technologies, which can make functioning in a workplace a problem [13].

This is an area not often mentioned in the field of universal design, and would include issues like which requirements can be made to design of mainstream technology, for instance in the shape of human factors engineering, to ensure that people can use products and interact with characteristics of products, in different environments? How to ensure that human factors engineering considers the capacities of persons with different disabilities (like hearing, visual or mobility impairments) so that they can interact with such technologies?

\section{9. 'What can accessible solutions do to ensure an inclusive labor market for elderly employees?}

So far, we have looked at the general issues of elderly workforce and accessibility to workplaces, provided an overview of present technical solutions, and also presented some of the challenges facing users with age-related disabilities regarding the use of the technological solutions.

We can establish that the challenges regarding new, digitalized working tools can in many cases exclude workers who, because of their disabilities, cannot use these tools if they are not accessible. There is thus a real danger that new digital work tools can lead to discrimination and exclusion in the labor market, rather than inclusion and societal benefits. To avoid this, much responsibility lies on the ability of the management of a workplace to foresee such problems by ensuring that the software and hardware, automats and other equipment follow the normal requirements of accessibility and universal design.

However, accessibility of the working tools is not enough to keep elderly workers in the labor market or to facilitate that re-entering into work of this group - unless several measures are taken in combination. First, if an elderly worker has a need for assistive technology, like a screen reader or Braille terminal, measures must be taken to ensure a good interface between the AT and the working tool. The introduction of new Intranet software that is not accessible or inoperable with a Braille terminal is for instance enough to prevent a person from taking full part in the work, when she cannot read important information on the Intranet.

Second, there must be resources present to ensure good training in the operation of new work-related digitalized tools. The training must be practical, but also have a view for further career development. Also, good support after the training should be made available for the individual worker. 


\section{Conclusion}

Universal design is a necessary principle to support inclusion for all with an ageing workforce but must be understood and implemented in a broader sense than "classic" adaptation to ensure barrier-free physical surroundings. It also includes areas like services, digitalization training and user interface between work related and assistive technologies. It makes demands to an enterprise's management system and training policy, besides mainstream human resources policies.

While universal design is definitively necessary as a tool to make digitalized system at workplaces inclusive for all, it is necessary to be aware that it must be complemented with on-the-spot training, and access to support. Another important point is that elderly workers are not per definition unable to grasp new technology - on the contrary many are as experienced and knowledgeable of recent technological developments as any younger workers. Indeed, it should be part of management policy to ensure that there is organized a system for elderly workers to share their experience for younger employees on many fields of work.

\section{References}

[1] https://standards.cen.eu/dyn/www/f?p=204:110:0::::FSP_PROJECT,FSP_ORG_ID:62323,2301962\&cs= 1D28CFDC66E7CEF3CE441294CAA9FEABE

[2] https://www.un.org/development/desa/disabilities/convention-on-the-rights-of-persons-withdisabilities.html

[3] From EN 17161 Design for All - Accessibility following a Design for All approach in products, goods and services - Extending the range of users

[4] Calzavara, M., Battini, D., Bogataj, D., Sgarbossa, F. and Zennaro, I. (2019). Ageing workforce management in manufacturing systems: state of the art and future research agenda. International Journal of Production Research, 1-19.

[5] See https://www.microsoft.com/en-us/ai/seeing-ai

[6] See https://blogs.microsoft.com/ai/ai-powered-captioning/

[7] See https://www.etsi.org/deliver/etsi_en/301500_301599/301549/02.01.02_60/en_301549v020102p.pdf

[8] See information (in Norwegian): https://www.standard.no/standardisering/Komiteer/sn/snk-592/

[9] See for instance https://sid.usal.es/idocs/F8/FDO20694/provisionassistivetechnology.pdf

[10] See also: https://spekter.no/Global/Rapporter/Eksterne_rapporter/AFIrapport $\% 20$ rekruttering $\% 20$ nedsatt $\% 20$ funksjon.pdf

[11] $\mathrm{MI}$ is a method to support persons who for different reasons are not in employment (for instance unemployed, people on long-term sick leave etc.), to return to employment. Three out of five case studies found that the use of MI can lead to more people coming back to work.

[12] See for instance Calzavara, M., Battini, D., Bogataj, D., Sgarbossa, F. and Zennaro, I. (2019). Ageing workforce management in manufacturing systems: state of the art and future research agenda. International Journal of Production Research, 1-19.

[13] There are several good resources for assessing solutions for accessible ICT that can be used at workplaces, for instance https://digileaders.com/the-business-case-for-accessibility-and-inclusivedesign/ - this is a website describing the benefits for an enterprise if they ensure that their products and services are accessible; https://bighack.org/literature-review/ is an overview of literature on the benefits of accessible products and services, both of them from United Kingdom.

https://www.idsa.org/awards/idea/design-strategy/ncr-accessibility-strategy-and-features is an American website on accessible automats of different kinds; https://www.philips.com/aw/about/philips-design/design-in-action.html is a Dutch website on how their company work on inclusive design. Finally, https://www.telenor.no/openmind/ and https://www.telenor.no/openmind/modellen/ are Norwegian webpages in a projects run by the Norwegian telecom company Telenor, which is including disabled persons through the use of digital tools to prepare them to enter or reenter the labor market. 